\title{
Sweet Cherry Skin Has a Less Negative Osmotic Potential than the Flesh
}

\author{
Eckhard Grimm and Moritz Knoche ${ }^{1}$ \\ Institute for Horticultural Production Systems, Leibniz-University Hannover, Herrenhäuser Straße 2, \\ 30419 Hannover, Germany
}

\begin{abstract}
AdDitional INDEX words. Prunus avium, epidermis, exocarp, mesocarp, turgor, water potential
Abstract. The skin is the primary load-bearing structure in a sweet cherry fruit (Prunus avium L.). Failure of the skin in rain cracking is considered to be related to water uptake. Little is known of the skin's water potential, its osmotic potential $\left(\Psi_{\Pi}\right.$ ) , and turgor. The objective here was to quantify $\Psi_{\Pi}$ s relative to the osmotic potential of the flesh $\left(\Psi_{\Pi}{ }^{F}\right)$. Spatial resolution was achieved by monitoring plasmolysis in epidermal cells in tissue sections, incubated in selected osmotica using a light microscope method. Decreasing the osmotic potential [ $\Psi_{\Pi}$ (more negative)] of the incubation medium increased the proportion (percent) of plasmolyzed epidermal cells. The pattern of increasing plasmolysis was sigmoidal with increasing osmolyte concentration. The value of $\Psi_{\Pi}$ for $50 \%$ of cells plasmolyzed, depended to some extent on the osmolyte used. The value of $\Psi_{\Pi}$ became slightly less negative for the osmolytes tested in the order: 1) mannitol, 2) sucrose, and 3) artificial cherry juice (a solution comprising the five major osmolytes of sweet cherry juice in the appropriate proportions and concentrations). There was little difference in the value of $\Psi_{\Pi}$ at $50 \%$ plasmolysis between the cultivars Hedelfinger, Sam, and Sweetheart. In all three cultivars, the value of $\Psi_{\Pi}{ }^{F}$ (measured for expressed juice using an osmometer) was markedly more negative than that of $\Psi_{\Pi 1} \mathbf{s}$ (measured for $50 \%$ plasmolysis). Incubating skin segments in juice from the same fruit resulted in the plasmolysis of most $(85.7 \%$ to 96.4\%) of the epidermal cells. As fruit development progressed from stage II [27 day after full bloom (DAFB)] to the fully mature stage III (97 DAFB), plasmolysis occurred for increasingly more negative values of $\Psi_{\Pi I}$. Moreover, the difference between the osmotic potential values recorded for the flesh $\Psi_{\Pi}{ }^{F}$ and for the skin $\Psi_{\Pi}$ increased. Plasmolysis of epidermal cells was accompanied by a marked swelling of their walls. The results indicate a marked difference in the osmotic potential of flesh $\left(\Psi_{\Pi}{ }^{F}\right.$ trended more negative) and skin cells $\left(\Psi_{\Pi}\right.$ s trended less negative).
\end{abstract}

The water potential $(\Psi)$ of the sweet cherry fruit and its two components, osmotic potential $\left(\Psi_{\Pi}\right)$ and turgor $\left(\Psi_{\mathrm{P}}\right)$ (where $\Psi=$ $\Psi_{\Pi}+\Psi_{\mathrm{P}}$ ), are likely to be important factors affecting fruit cracking. First, fruit $\Psi$ affects the rate of water uptake through the skin surface. Here, the rate is related to the difference between the value of $\Psi$ for an adhering water droplet (probably very close to zero) and that of the epidermis (Beyer and Knoche, 2002). Second, for vascular flow through the xylem of the pedicel, the flow rate will be related to the difference between the value of $\Psi_{\mathrm{P}}$ in the apoplast of the spur and the average value of $\Psi_{\mathrm{P}}$ in the apoplast of the fruit. Third, according to the critical turgor pressure concept, rain cracking is thought to be a function of fruit turgor in grapes [Vitis vinifera $\mathrm{L}$. (Considine and Kriedemann, 1972)] and also in sweet cherries (Measham et al., 2009). Here fruit (tissue) turgor is generated by the stress in the fruit skin, which envelopes the semifluid parenchyma of the flesh (Considine and Brown, 1981).

Despite its possible role in fruit cracking, little is known about the values taken by $\Psi$ and its components within the various tissues of a developing sweet cherry fruit. Till now, for sweet cherries, it is the situation prevailing in the large parenchyma cells of the flesh of the outer mesocarp that has received most attention with data now being available for the osmotic potential $\left(\Psi_{\Pi}^{\mathrm{F}}\right)$ and turgor of these cells $\left(\Psi_{\mathrm{P}}^{\mathrm{F}}\right)($ Knoche

Received for publication 5 May 2015. Accepted for publication 12 June 2015. This research was funded in part by a grant from the Deutsche Forschungsgemeinschaft.

We thank Friederike Schroeder, Henrik J. Schlegel, and Simon Sitzenstock for technical support, Drs. Sandy Lang and Bishnu P. Khanal for very helpful comments on an earlier version of this manuscript.

${ }^{1}$ Corresponding author. E-mail: moritz.knoche@obst.uni-hannover.de. et al., 2014; Schumann et al., 2014). The turgor of these cells is surprisingly low $\left(\Psi_{\mathrm{P}}^{\mathrm{F}} \approx\right.$ zero $)$ compared with their highly negative osmotic potentials $\left(\Psi_{\Pi}^{\mathrm{F}}\right)$, implying highly negative values for their water potentials $\left(\Psi^{\mathrm{F}}\right)$. The thin $[<100 \mu \mathrm{m}$ (Glenn and Poovaiah, 1989)] skin of a sweet cherry fruit forms its structural "backbone" (Brüggenwirth et al., 2014) holding the flesh under compression, the skin under tension, like a football (Grimm et al., 2012). However, similar information relating to the epidermal cells that (with the hypodermis) make up the fruit's skin is not yet available and is difficult to obtain. The desired values for the epidermis are the skin's water potential $\left(\Psi^{\mathrm{S}}\right)$ with its components $\Psi_{\Pi}^{\mathrm{s}}$ and turgor $\left(\Psi_{\mathrm{P}}^{\mathrm{S}}\right)$. These values are especially difficult to obtain because 1) the skin is quite thin and 2) the size of the epidermal cells is much smaller than the parenchyma cells of the flesh. This makes direct determination of cell turgor using a pressure probe difficult (Steudle, 1993). The only published information of which we are aware is based on osmometric measurements of juice extracted from $1 \pm 0.2$-mm-thick skin tissue samples (Moing et al., 2004). Based on their dataset, the value of $\Psi_{\Pi} \mathrm{s}$ for the outer 1-mm layer of the fruit was slightly less negative than that of the flesh beneath. However, the thin $(<100 \mu \mathrm{m})$ skin can have comprised only $\approx 10 \%$ or less of their 1-mm sample (Glenn and Poovaiah, 1989), so their result must have been dominated ( $90 \%$ or more) by the parenchyma cells immediately underlying the hypodermis and epidermis. Hence one might reasonably expect the true difference between $\Psi_{\Pi}{ }^{\mathrm{S}}$ and $\Psi_{\Pi}{ }_{\mathrm{F}}$ to be markedly greater than that reported by them. Nevertheless, direct evidence for our assertion is lacking.

The objective of this study was to measure the osmotic potential of the epidermal cells of sweet cherry fruit $\left(\Psi_{\Pi}^{\mathrm{S}}\right)$ relative to those of the flesh cells $\left(\Psi_{\Pi}{ }^{\mathrm{F}}\right)$. Because of the need for 
high spatial resolution, we used microscopy and a plasmolysis technique to limit our analyses just to the epidermal cell layer. The same values for the flesh were measured conventionally using osmometry.

\section{Materials and Methods}

Plant material. Fruit of the sweet cherry cultivars Adriana, Dönissens Gelbe, Flamengo Srim, Frühe Rote Mecklenburger, Hedelfinger, Rainier, Sam, Staccato, and Sweetheart, all grafted on Gisela 5 rootstocks (Prunus cerasus L. $\times$ Prunus canescens Bois), were sampled at commercial maturity as indexed by color, size, and taste. In addition, 'Regina' fruit was sampled during development from $27 \mathrm{~d}$ to maturity at 97 DAFB. Trees were grown in a greenhouse and an experimental orchard of the Horticultural Research Station of the Leibniz University in Ruthe (lat. $52^{\circ} 14^{\prime} \mathrm{N}$, long. $9^{\circ} 49^{\prime} \mathrm{E}$ ). Fruit were selected for freedom from defects and for uniformity, and transferred to the laboratory. Unless otherwise specified fruit was processed within $48 \mathrm{~h}$ of sampling.

GeNerAL EXPERIMENTAL PROCEDURE. Sections of the fruit skin comprising epidermal and hypodermal cells were prepared using a razor blade, blotted with tissue paper or rinsed by dipping briefly $(5 \mathrm{~s})$ in deionized water. A section was immediately transferred to a microscope slide, covered with a cover slip, and incubated for $30 \mathrm{~min}$ in an aqueous solution containing one of a broad range of concentrations of an osmolyte. Unless otherwise specified, sucrose was used as the standard osmolyte. After $30 \mathrm{~min}$, the slide was transferred to the stage of a microscope and viewed in incident transmitted light at $\times 40$ magnification using a fluorescence microscope (BX-60; Olympus Europa, Hamburg, Germany). Occasionally, differential interference contrast was used to enhance contrast. Unless otherwise specified, cells were observed only in sections that appeared healthy as indexed by the absence of coagulated protoplasts. Calibrated digital images were taken (DP 71, Olympus Europa) and the percentage of plasmolyzed cells was determined. In some experiments, swelling of the cell walls was quantified by determining cell wall thickness using image analysis (Cell-P, Olympus Europa). The osmolarity of incubation media and of juice extracted from the same fruit as that used in the plasmolysis and cell wall swelling assays was quantified by vapor pressure osmometry $\left(\mathrm{VAPRO}^{\circledR} 5520\right.$ and 5560; Wescor, Logan, UT).

EXPERIMENTS. The effects of osmolyte type and concentration on the percentage plasmolysis were investigated in 'Adriana' sweet cherry using sucrose, mannitol, or a mix of osmolytes that mimicked the composition of extracted sweet cherry juice. We refer to this solution as artificial cherry juice. Where solubility permitted, osmolarities ranged from 0 to $5 \mathrm{MPa}$ (equivalent to 0 to $2000 \mathrm{mmol} \cdot \mathrm{kg}^{-1}$ ). For the artificial juice, a $1000 \mathrm{mmol} \cdot \mathrm{kg}^{-1}$ solution was composed of glucose (431.8 mM), fructose (393.5 mM), sorbitol (76.9 mM), malic acid (13.8 $\mathrm{mm})$, and potassium malate (56.3 mm) (Herrmann, 2001). These five osmolytes accounted for $98 \%$ of the osmolarity recorded for sweet cherry juice. The $\mathrm{pH}$ of the artificial juice ( $\mathrm{pH}$ 3.4) was close to that of natural sweet cherry juice ( $\mathrm{pH} 3.6)$. The percentage of plasmolyzed cells was quantified as described above on sections excised from five fruit per osmolyte type.

Differences in the osmolarity of the skin and flesh were investigated in 'Hedelfinger', 'Sam', and 'Sweetheart' fruit.
The osmolarity of the epidermis was assessed by quantifying the percentage of plasmolysis of fruit skin sections after $30 \mathrm{~min}$ of incubation in sucrose solutions and that of the flesh by water vapor pressure osmometry of expressed juice. Sections were prepared from 10 fruits per cultivar.

Plasmolysis was also determined following incubation of skin sections in juice extracted from flesh of the same fruit in the immediate vicinity of the position where the skin section was excised. Plasmolysis was assessed after $30 \mathrm{~min}$. Segments incubated in silicone oil (AK 10; Wacker Chemie, Munich, Germany) served as controls and were inspected immediately after excision. To broaden the database, this experiment was also conducted with 'Dönissens Gelbe', 'Flamengo Srim', 'Frühe Rote Mecklenburger', 'Hedelfinger', 'Rainier', 'Sam', and 'Staccato'. Two sections per fruit from a total of 10 fruit per cultivar were assessed.

The effect of development on the osmolarity of epidermal cells as indexed by plasmolysis was studied in developing 'Regina' (27 to 97 DAFB). Sections of the fruit skin were prepared, incubated in sucrose solutions (30 $\mathrm{min})$, photographed, and the percentage of plasmolyzed cells and thickness of cell walls were quantified as described above. This procedure allowed direct comparisons between cell wall thickness and the extent of plasmolysis on an individual skin segment basis. The number of replicates was 10 . Data for the osmolarity of the flesh of the fruit (obtained from the same batch of fruit) were taken from Schumann et al. (2014).

The time course of cell wall swelling was established using skin sections from 'Sam' sweet cherry $(n=5)$. Because cells burst when incubated in water for extended periods of time, incubation was ended after $3 \mathrm{~h}$. By this time, the majority of protoplasts were still intact and alive so that swelling could be established on an individual segment basis.

Potential relationships between the swelling of cell walls and the initial cell wall thickness were identified in 'Sam' sweet cherry by quantifying cell wall thickness within 5 min of excision of skin segments and then repeating the measurement on the same segment at the same position $3 \mathrm{~h}$ later. Fruit used in this experiment was held at $2{ }^{\circ} \mathrm{C}$ for 5 to $6 \mathrm{~d}$.

Whether cell wall swelling was affected by the health (or otherwise) of neighboring epidermal cells was studied in 'Sweetheart'. In these experiments, a polyethylene glycol solution was used that was osmotically buffered at an osmolarity of $200 \mathrm{mmol} \cdot \mathrm{kg}^{-1}$. A 6-h incubation period was selected. Under these conditions, some protoplasts collapsed as indexed by their coagulated cytoplasm and epidermal sections contained both healthy and collapsed cells. Cell wall thickness was measured between two healthy epidermal cells, between a living cell and a dead cell and between two dead cells. Three measurements were made per pair of cells and section on a total of 20 fruit.

DAta ANALyses. Results in tables and figures are presented as means \pm SE. Where error bars are not visible, they are smaller than the symbols. Analyses of variance (PROC GLM) and regression analyses (PROC REG, PROC NLIN) were carried out using SAS (version 9.1.3; SAS Institute, Cary, NC). Percentage plasmolysis data were arcsine transformed before analysis of variance. The osmolarity at $50 \%$ plasmolysis was estimated as the point of inflection of a logistic regression model. At this osmolarity, the turgor pressure is zero (the point of insipient plasmolysis) and the osmolarity of the symplast is assumed to be equal to that of the incubation solution. 


\section{Results}

Plasmolysis occurred when skin sections were incubated in hypertonic sucrose solutions. Vacuoles and protoplasts of some epidermal cells shrank, so that the cell membranes separated and receded from the cell walls (Fig. 1A-C). As the osmotic potential of the incubation medium fell (became more negative with increasing concentration of osmolytes) so the percentage of plasmolyzed epidermal cells increased. The profile of the plasmolysis increase was sigmoidal with falling osmotic potential (Fig. 2A). When different osmolytes were compared, the osmotic potential associated with 50\% plasmolysis changed. Thus, the osmotic potential with mannitol as osmolyte was less negative $(-0.8 \pm 0.1 \mathrm{MPa})$, than with sucrose $(-1.2 \pm$ $0.0 \mathrm{MPa})$, than with artificial sweet cherry juice $(-1.4 \pm 0.0$ $\mathrm{MPa})$. It was also observed that juice extracted from the flesh had an osmotic potential of $-1.9 \pm 0.0 \mathrm{MPa}$. This value is significantly more negative than the osmotic potentials of any of the pure osmolytes or of the artificial juice for the $50 \%$ plasmolysis condition in the epidermis.

When skin segments of 'Hedelfinger', 'Sam', and 'Sweetheart' were incubated in solutions of different osmolarities, the relationships observed between percentage plasmolysis and osmotic potential were qualitatively and quantitatively similar
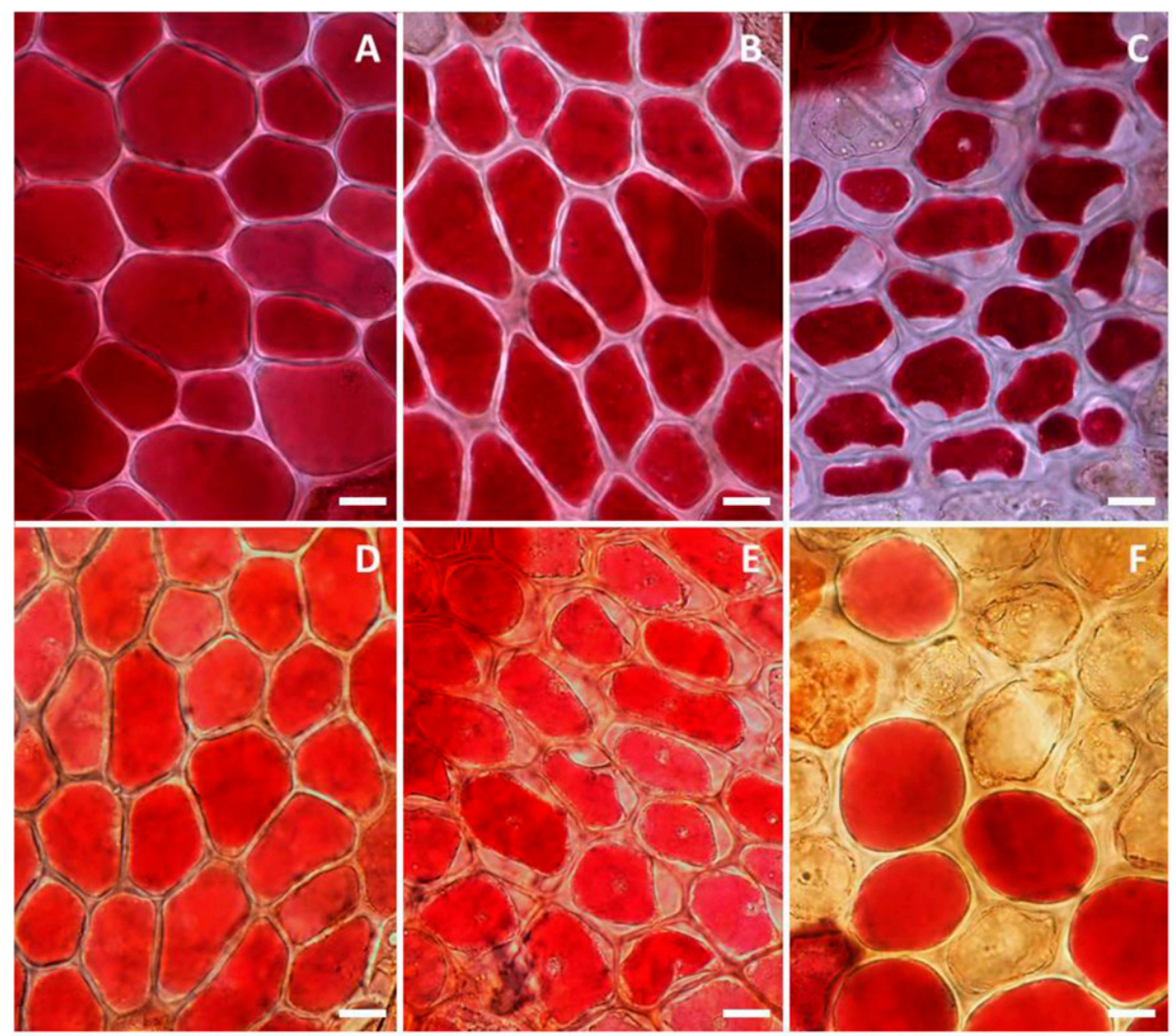

Fig. 1. Representative images of sections of the epidermis of mature 'Sam' sweet cherry fruit after a 30-min incubation in water (A) or sucrose solutions at osmolarities of $1.0 \mathrm{MPa}(\mathbf{B})$ and $2.5 \mathrm{MPa}(\mathbf{C})$. (D and E) Epidermal sections of 'Frühe Rote Mecklenburger' immediately after excision (D) and after a 30-min incubation in sweet cherry juice extracted from flesh of the same fruit immediately underneath the skin (E). (F) Epidermal section of 'Sweetheart' after $6 \mathrm{~h}$ of incubation in $0.5 \mathrm{MPa}$ polyethylene glycol 6000 demonstrating cell wall swelling between dead cells (as indexed by the loss of anthocyanin) and nonswollen cell walls between living cells (as indexed by the presence of an anthocyanin-containing vacuole). All scale bars $20 \mu \mathrm{m}$.
(Fig. 2B). In all cultivars examined, the osmotic potential of the flesh was markedly more negative than that of the epidermal cells of the same individual fruit (Table 1). Across all cultivars and fruit, the average difference was $1.1 \mathrm{MPa}$ [range 0.8 to 1.5 of osmolytes (Fig. 2A) and the comparison of cultivars (Fig. 2B), a marked difference (up to $1 \mathrm{MPa}$ and more) existed between the least and the most negative osmotic potentials of bolutions causing plasmolysis in a fraction of the population of epidermal cells (insets in Fig. 2A and B). Thus, the distribution of osmotic potentials of epidermal cells must been broad.

en skin segments of selected sweet cherry cultivars were in juice extracted from the same batch of fruit, epidermal plasmolysis was the general result (Fig. 1D and E). In six out of seven cultivars, between $85.7 \%$ and $96.4 \%$ of epidermal cells were plasmolyzed. This indicates that the skin fruit (Table 2). 'Flamengo Srim' differed from all other cultivars examined in that 1 ) the percentage of epidermal cells plasmolyzed in juice from the same fruit was lower but still significantly higher than in the control and 2) a significant proportion of epidermal cells exhibited granulated cytoplasm and showed no indication of plasmolysis.

Plasmolysis depended on the stage of development (Fig. 3). As fruit developed from stage II (27 DAFB) to full maturity at stage III (97 DAFB), plasmolysis occurred at increasingly more negative osmotic potentials. A comparison of fruit of different developmental stages revealed that 1) osmotic potentials of flesh and skin decreased steadily (became increasingly negative) with the largest change occurring around the stage II/III transition, 2) skin osmotic potentials were always less negative than those of the flesh, and 3 ) the osmotic potential difference between flesh and skin increased steadily with development (Fig. 4A-C).

Plasmolysis of epidermal cells was accompanied by a marked swelling of their cell walls (Fig. 1B and C). The time-course experiment established that swelling approached an asymptote within $\approx 3 \mathrm{~h}$ (Fig. 5A). Furthermore, the thickness of the swollen cell walls (after $3 \mathrm{~h}$ ) was linearly related to their initial thickness (Fig. 5B). Because the slope of the linear regression was close to unity (slope $0.88 \pm 0.09 ; r^{2}=0.85$, $P<0.001)$, the amount of cell wall swelling was essentially independent of initial cell wall thickness. The increase in cell wall thickness averaged $\approx 0.64 \pm 0.15 \mu \mathrm{m}$.

The extent of cell wall swelling depended on the health of the cells 

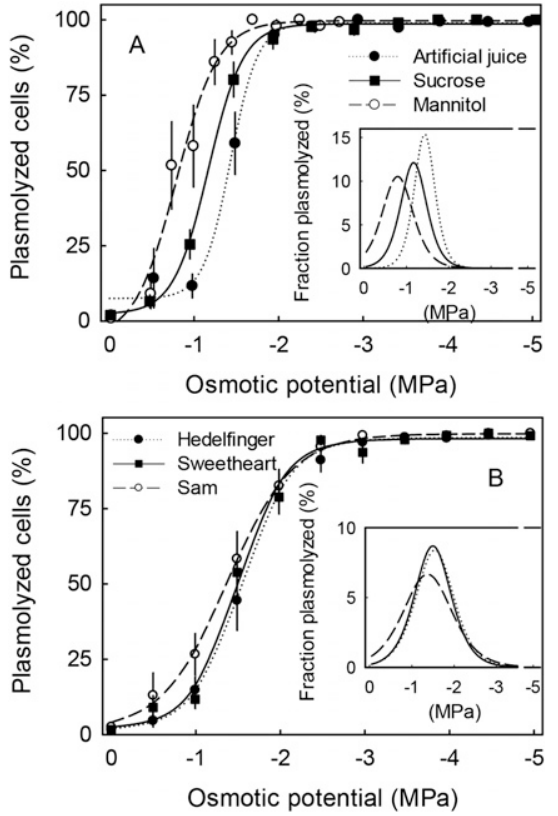

Fig. 2. Plasmolysis of epidermal cells of mature 'Adriana' sweet cherry fruit. (A) Effect of sucrose, mannitol, or of a solution comprising the five dominant osmolytes in sweet cherry juice ["artificial juice" composed of glucose, fructose, sorbitol, malic acid, and potassium malate (Herrmann, 2001)]. (B) Effect of sucrose on plasmolysis in skin segments of mature 'Hedelfinger', 'Sam', and 'Sweetheart'. Insets in A and B: Fraction of cells plasmolyzing as a function of the osmolarity of the bathing solutions. The fraction of cells plasmolyzing at the respective osmolarity was calculated as the first derivative of the logistic regression line depicted in the main graphs.

Table 1. Mass, osmotic potential of extracted juice from the flesh $\left(\Psi_{\Pi}^{\mathrm{F}}\right)$, and of the cytoplasm of epidermal cells $\left(\Psi_{\Pi}^{\mathrm{S}}\right)$ of mature sweet cherry fruit of selected cultivars. The value of $\Psi_{\Pi}{ }^{\mathrm{s}}$ was estimated as the osmolarity of a sucrose solution that causes $50 \%$ of the epidermal cells to plasmolyze. The gradient in osmotic potential $\left(\Delta \Psi_{\Pi}\right)$ was calculated by subtracting $\Psi_{\Pi}{ }^{\mathrm{F}}$ from $\Psi_{\Pi}{ }^{\mathrm{s}}$.

\begin{tabular}{|c|c|c|c|c|}
\hline & Mass & $\Psi_{\Pi}^{\mathrm{F}}$ & $\Psi_{\Pi}{ }^{\mathrm{s}}$ & $\Delta \Psi_{\Pi}$ \\
\hline Cultivar & $\overline{[\text { mean } \pm \text { SE (g/fruit) }]}$ & \multicolumn{3}{|c|}{$[$ mean \pm SE $(\mathrm{MPa})]$} \\
\hline Adriana & $9.3 \pm 0.1 \mathrm{c}^{\mathrm{z}}$ & $-1.9 \pm 0.0 \mathrm{c}$ & $-1.2 \pm 0.0$ & $0.8 \pm 0.1$ \\
\hline Hedelfinger & $9.4 \pm 0.2 \mathrm{c}$ & $-2.7 \pm 0.1 \mathrm{ab}$ & $-1.5 \pm 0.0$ & $1.2 \pm 0.1$ \\
\hline Regina & $12.5 \pm 0.2 \mathrm{a}$ & $-2.8 \pm 0.1 \mathrm{ab}$ & $-1.7 \pm 0.1$ & $1.1 \pm 0.1$ \\
\hline Sam & $10.2 \pm 0.2 \mathrm{~b}$ & $-2.5 \pm 0.1 b$ & $-1.4 \pm 0.1$ & $1.2 \pm 0.1$ \\
\hline Sweetheart & $9.1 \pm 0.4 \mathrm{c}$ & $-3.0 \pm 0.1 \mathrm{a}$ & $-1.5 \pm 0.0$ & $1.5 \pm 0.1$ \\
\hline Grand mean & $10.0 \pm 0.5$ & $-2.6 \pm 0.2$ & $-1.4 \pm 0.1$ & $1.1 \pm 0.2$ \\
\hline
\end{tabular}

${ }^{\text {zMean separation within columns by Tukey's Studentized range test at }}$ $P=0.05$.

Table 2. Osmolarity of flesh and percentage of plasmolysis of epidermal cells when incubated in juice extracted from the flesh of selected sweet cherry cultivars at maturity.

\begin{tabular}{lccc}
\hline & $\begin{array}{c}\text { Osmolarity flesh } \\
\text { Cultivar }\end{array}$ & \multicolumn{2}{c}{ Plasmolysis [mean \pm SE (\%)] } \\
\cline { 3 - 4 } Dönissens Gelbe & \multicolumn{1}{c}{ Control } & Juice \\
\hline Flamengo Srim & $3.3 \pm 0.1 \mathrm{a}^{\mathrm{z}}$ & $4.1 \pm 1.0 \mathrm{a}$ & $86.9 \pm 2.2 \mathrm{~b}$ \\
Frühe Rote Mecklenburger & $2.5 \pm 0.0 \mathrm{~d}$ & $6.3 \pm 1.3 \mathrm{a}$ & $29.5 \pm 2.7 \mathrm{c}$ \\
Hedelfinger & $2.5 \pm 0.0 \mathrm{~d}$ & $10.2 \pm 3.8 \mathrm{a}$ & $85.7 \pm 2.5 \mathrm{~b}$ \\
Rainier & $2.7 \pm 0.0 \mathrm{~cd}$ & $4.8 \pm 1.5 \mathrm{a}$ & $88.9 \pm 2.1 \mathrm{~b}$ \\
Sam & $3.0 \pm 0.0 \mathrm{ab}$ & $2.8 \pm 1.2 \mathrm{a}$ & $89.2 \pm 2.2 \mathrm{~b}$ \\
Staccato & $2.9 \pm 0.1 \mathrm{bc}$ & $10.7 \pm 3.2 \mathrm{a}$ & $96.4 \pm 1.0 \mathrm{a}$ \\
& $3.1 \pm 0.0 \mathrm{ab}$ & $6.7 \pm 1.9 \mathrm{a}$ & $91.5 \pm 1.8 \mathrm{ab}$ \\
\hline
\end{tabular}

${ }^{\mathrm{z}}$ Mean separation within columns by Tukey's Studentized range test at $P=0.05$. bordering a particular cell wall. Cell wall swelling was greatest for a cell wall between two nonliving cells and least when both bordering cells were healthy and fully turgid. The extent of cell wall swelling was intermediate for a cell bordering a healthy cell on one side and a nonliving one on the other (Fig. 1F; Table 3).

Cell wall swelling depended on the osmotic potential of the incubation medium and on the developmental stage of the fruit (Fig. 3). Before 55 DAFB, cell wall thickness was nearly independent of the osmotic potential of the bathing solution indicating the absence of significant swelling. As fruit development progressed to 55 DAFB during stage III and beyond, cell wall thickness increased under more negative osmotic potential conditions in a manner consistent with swelling. When cell wall thickness is considered as a function of the percentage of plasmolyzed cells, for stages $<55$ DAFB, cell wall thickness was essentially independent of the extent of plasmolysis (Fig. 6A and B). However, beyond 55 DAFB, cell wall thickness increased markedly and approached an asymptote as cells began to plasmolyze and turgor pressures most likely approached zero (Fig. 6B).

\section{Discussion}

Our data clearly establish that 1) for ripening sweet cherries, most individual fruit, of most cultivars, the value of $\Psi_{\Pi}^{\mathrm{s}}$ (skin) is less negative than that of $\Psi_{\Pi}{ }^{\mathrm{F}}$ (flesh) with the result that almost all epidermal cells suffer plasmolysis when exposed to juice from their own fruit [this includes even those few individual epidermal cells lying close to the extreme (negative) end of the osmotic potential demographic]; 2) the difference, $\Delta \Psi_{\Pi}$, (where $\Delta \Psi_{\Pi}=\Psi_{\Pi}{ }^{\mathrm{S}}-\Psi_{\Pi}{ }^{\mathrm{F}}$ ) between skin and flesh increases during stage III averaging 1.1 MPa across cultivars at maturity; and 3) plasmolysis is accompanied by marked swelling of the cell walls.

EVIDENCE FOR A LESS NEGATIVE OSMOTIC POTENTIAL IN SKIN THAN FLESH. The less negative osmotic potential of skin than flesh is consistent with earlier data by Moing et al. (2004) who reported a difference in $\Psi_{\Pi}$ of $0.5 \mathrm{MPa}$ (range in $\Delta \Psi_{\Pi}=0.4$ to $0.7 \mathrm{MPa}$ ). The $\Delta \Psi_{\Pi}$ values in our study were 2- to 3-fold larger than those of Moing et al. (2004) probably because of our much higher spatial resolution achievable by a microscope assessment of epidermal plasmolysis, whereas Moing et al. (2004) quantified juice osmolarity from $1.0 \pm 0.2$-mm thick tissue blocks, where only the outer $\approx 100 \mu \mathrm{m}(\approx 10 \%)$ was epidermal (Glenn and Poovaiah, 1989) and most of the rest $(\approx 90 \%)$ was parenchymatous. Hence, in their samples, the juice from the true skin (having a less negative $\Psi_{\Pi}^{\mathrm{s}}$ ) was mixed with that from some adhering parenchyma cells beneath (having a more negative $\Psi_{\Pi}^{\mathrm{F}}$ ), probably resulting in an underestimate of the magnitude of $\Delta \Psi_{\Pi \text {, the }}$ difference in osmotic potential between skin and flesh.

The conclusion that osmotic potential differs between skin and flesh is based on different techniques (i.e., plasmolysis for the skin vs. osmometry of the flesh). Unfortunately, it was technically impossible to observe plasmolysis in a parenchyma cell of the flesh (cells far too large) or, conversely, to use 


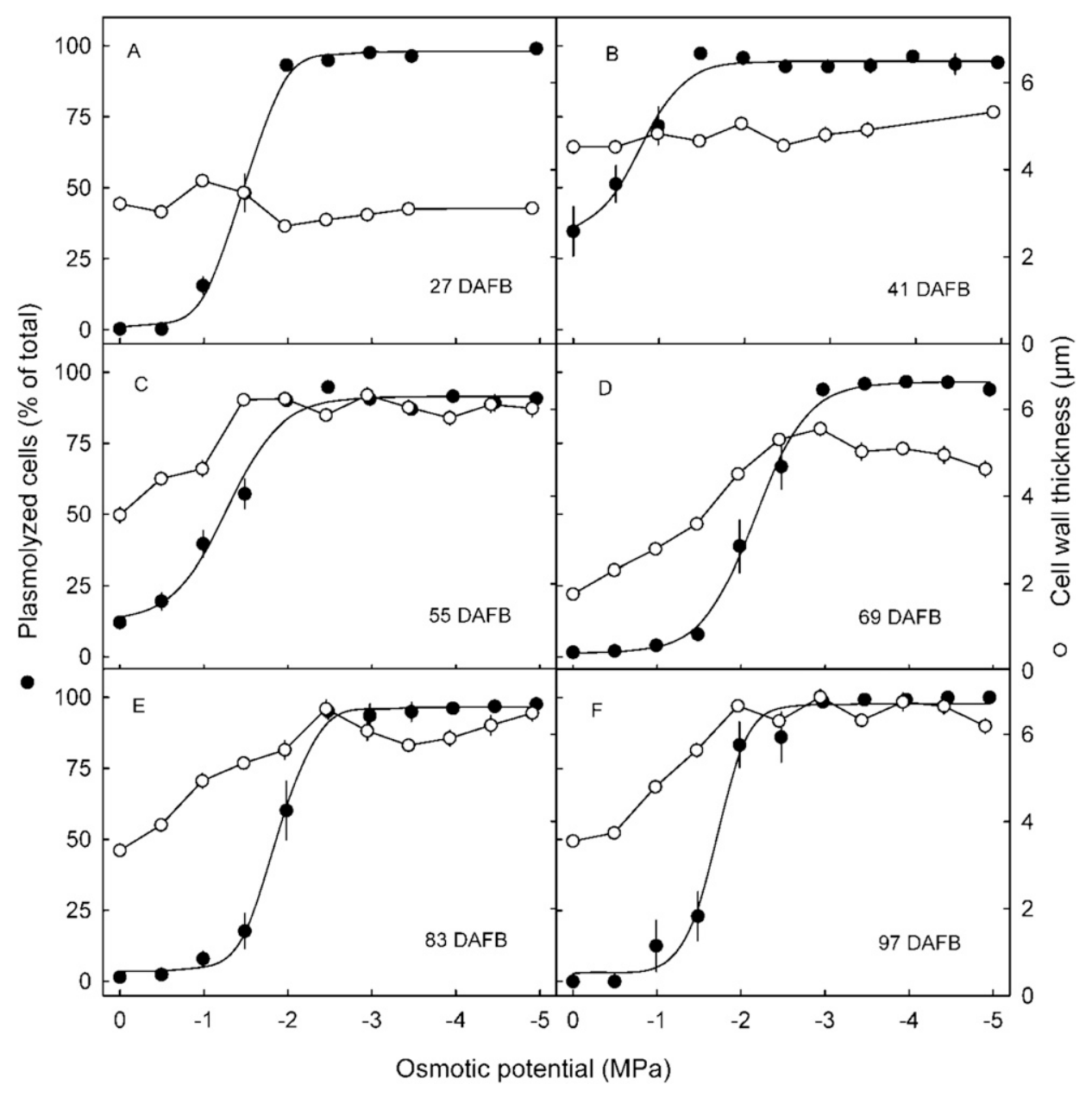

Fig. 3. Effect of the osmotic potential of sucrose solutions on the percentage of plasmolyzed epidermal cells and on the thickness of cell walls in developing 'Regina' sweet cherry fruit at 27 (A), 41 (B), 55 (C), 69 (D), 83 (E), and 97 (F) d after full bloom (DAFB). The osmolarity of the epidermal cells $\left(\Psi_{\Pi}\right.$ s) corresponded to the osmolarity of the sucrose solutions that yielded $50 \%$ plasmolysis. potential. Relaxation is rapid [halftime of $\approx 2.7 \mathrm{~min}$ (Grimm et al., 2012)] and this is accompanied by a decrease in planar area of the sample and consequently in the planar area of each epidermal cell. Cell wall strain release allows each epidermal cell to assume a more spherical shape and hence a decrease in turgor and thus a more negative water potential than before. If the skin sample is now bathed in an excess volume of an external solution, epidermal water potential will soon come into balance with this and the result will be a generally too-negative estimate of epidermal water potential. This suggests, the true difference in osmotic potential between flesh and skin is actually greater than that quantified above - in other words our estimate is conservative and the true difference will more likely be greater than (not less than) that we suggest.

$\Psi_{\Pi}{ }^{\mathbf{F}}$ : Juice extraction by crushing the flesh tissue will destroy any in vivo compartmentation and hence will create a potential for autolysis. What is the likelihood that enzyme reactions will significantly alter (decrease) juice osmotic potential? We have already seen that the predominant juice osmolytes are the hexose monomers glucose and fructose (Herrmann, 2001) and these are less likely to be affected with any rapidity. Sucrose is a possible candidate for rapid enzymatic cleavage but this moiety occurs at a too-low concentration for its possible autolytic cleavage to markedly decrease juice osmotic potential (Herrmann, 2001). a vapor pressure osmometer to record the osmotic potential of an epidermal cell (cells far too small). The large, thin-walled parenchyma cells prevent critical assessment of the onset of plasmolysis in the narrow focal plane of the microscope. Moreover, the soft flesh tissues of a mature fruit are difficult to handle in thin sections that require the absence of mechanical stress and minimal juice leakage. Nevertheless, we believe a methodological artifact is an unlikely explanation for the $\Delta \Psi_{\Pi}$ value we infer between skin and flesh. Furthermore, the observation that epidermal cells consistently plasmolyze when incubated in juice from the very same fruit would seem to offer conclusive and direct evidence for the existence of a major difference in $\Psi_{\Pi}$ between skin and flesh. Lastly, the significant value for $\Delta \Psi_{\Pi}$ we report here is not a singular event at one point in the course of development, but is present throughout stage III during which time it increases continuously (Fig. 4C).

Methodological artifacts. It is important to understand potential methodological limitations of this study as they affect the estimates both of $\Psi_{\Pi}{ }^{\mathrm{S}}$ and of $\Psi_{\Pi}^{\mathrm{F}}$ and, hence, of $\Delta \Psi_{\Pi}$.

$\Psi_{\Pi}$ s: The excision of a skin strip for microscopy allows its relaxation (release of elastic strain) and this may have altered the water
We suggest that the net effect of any methodological artifacts will more likely decrease the measured osmotic potential difference $\left(\Delta \Psi_{\Pi}\right)$ we report, than increase it. Hence, our inferences are satisfactorily conservative.

ARE SKIN AND FLeSh AT WATER POTENTIAL EQUilibrium? A central question is whether skin and flesh are at water potential equilibrium or could their water potentials differ significantly?

A water potential equilibrium implies the absence of a net movement of water and/or of osmolytes between flesh and skin. Under equilibrium conditions, $\Psi^{\mathrm{F}}=\Psi^{\mathrm{S}}$ and, hence,

$$
\Psi_{\Pi}^{\mathrm{F}}+\Psi_{\mathrm{P}}^{\mathrm{F}}=\Psi_{\Pi}^{\mathrm{S}}+\Psi_{\mathrm{P}}^{\mathrm{S}}
$$

where the much more negative value taken by $\Psi_{\Pi}{ }^{\mathrm{F}}$ than by $\Psi_{\Pi} \mathrm{s}$ requires $\Psi_{\mathrm{P}}^{\mathrm{F}}$ to be correspondingly much higher (i.e., much more positive) than $\Psi_{\mathrm{P}}^{\mathrm{S}}$. Rearranging the above equation

$$
\Psi_{\Pi}^{\mathrm{F}}-\Psi_{\Pi}^{\mathrm{S}}=\Psi_{\mathrm{P}}^{\mathrm{S}}-\Psi_{\mathrm{P}}^{\mathrm{F}}
$$

shows that under equilibrium conditions, $\Delta \Psi_{\Pi}$ and $\Delta \Psi_{\mathrm{P}}$ must be numerically equal. This would seem to imply that $\Psi_{\mathrm{P}}{ }^{\mathrm{F}}$ must greatly exceed $\Psi_{\mathrm{P}}^{\mathrm{S}}$ and that it would do so by an average of 1.1 $\mathrm{MPa}$ (Table 1). However, recorded values of $\Psi_{\mathrm{P}}^{\mathrm{F}}$ of mature fruit 


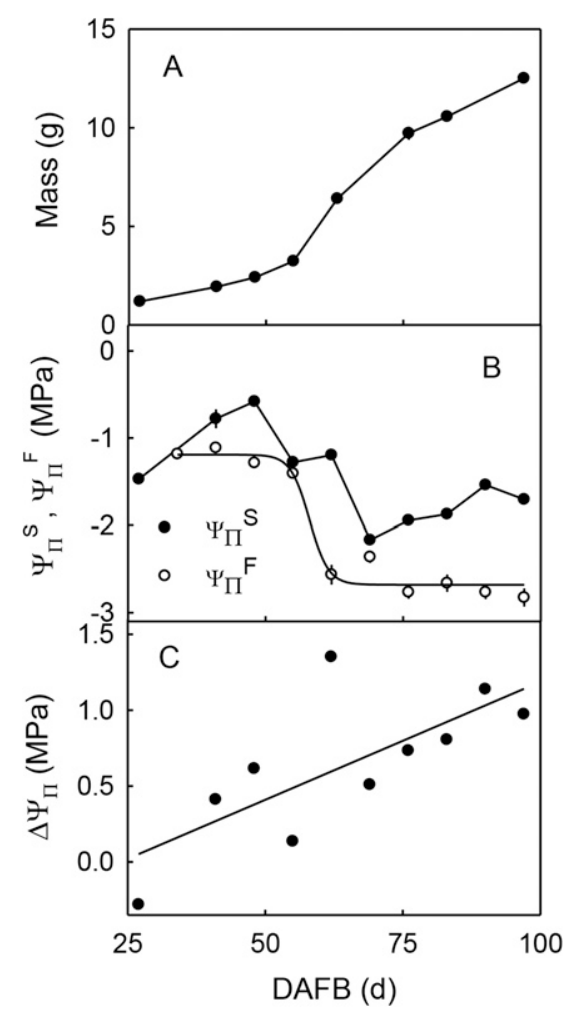

Fig. 4. (A) Developmental time course of change in mass, (B) osmotic potential of the skin as determined by plasmolysis $\left(\Psi_{\Pi}{ }^{\mathrm{S}}\right)$ and of juice extracted from the flesh $\left(\Psi_{\Pi}{ }^{F}\right)$ of developing 'Regina' sweet cherry fruit. Data for $\Psi_{\Pi}{ }^{F}$ were obtained by vapor pressure osmometry from the fruit of the same batch (redrawn from Fig. 2A in Schumann et al., 2014) for comparison. Data for $\Psi_{\Pi} \mathrm{S}$ represent osmolarities of the incubation solutions yielding $50 \%$ plasmolysis (Fig. 3). (C) Gradient in osmotic potential $\left(\Delta \Psi_{\Pi}\right)$ between skin and flesh. The $\Delta \Psi_{\Pi}$ value was calculated by subtracting $\Psi_{\Pi}{ }^{\mathrm{F}}$ from $\Psi_{\Pi}{ }^{\mathrm{S}}$. X-axis scale in days after full bloom (DAFB).

are always very much less than $1.1 \mathrm{MPa}$, indeed they usually take values of less than $10 \%$ of this value $[\approx 0.1 \mathrm{MPa}$ (Knoche et al., 2014; Schumann et al., 2014)]. This would seem to imply a highly negative value for $\Psi_{\mathrm{P}}^{\mathrm{s}}$, which inference is difficult to accept as being real. Thus, a high value for $\Psi_{\mathrm{P}}{ }^{\mathrm{F}}$ can be excluded as a mechanism for balancing the very negative value of $\Psi_{\Pi}^{\mathrm{F}}$.

In grape berries, high values for $\Psi_{\mathrm{P}}{ }^{\mathrm{F}}$ as a consequence of similarly very negative values for $\Psi_{\Pi}{ }^{\mathrm{F}}$ have been shown to be prevented by the accumulation of osmolytes in the apoplast (Wada et al., 2008, 2009). Here, the high levels of apoplastic osmolytes roughly balance the high symplastic ones, thereby preventing the development of a high $\Psi_{\mathrm{P}}^{\mathrm{F}}$. If this situation was also to occur in sweet cherry, then Eq. [1] must be modified by relaxing its implicit assumption that the apoplasts of the flesh and skin are essentially composed of pure water. This means we must include the opportunity for an apoplastic osmolyte in the notation for the flesh tissue $\left(\Psi_{\Pi}{ }^{\mathrm{Fa}}\right)$, not just a symplastic one $\left(\Psi_{\Pi}{ }^{\mathrm{Fs}}\right)$ and likewise in the skin $\left(\Psi_{\Pi}^{\mathrm{Sa}}\right.$ and $\left.\Psi_{\Pi}^{\mathrm{Ss}}\right)$.

$$
\left(\Psi_{\Pi}^{\mathrm{Fs}}-\Psi_{\Pi}^{\mathrm{Fa}}\right)+\left(\Psi_{\mathrm{P}}^{\mathrm{Fs}}-\Psi_{\mathrm{P}}^{\mathrm{Fa}}\right)=\left(\Psi_{\Pi}^{\mathrm{Ss}}-\Psi_{\Pi}^{\mathrm{Sa}}\right)+\left(\Psi_{\mathrm{P}}^{\mathrm{Ss}}-\Psi_{\mathrm{P}}^{\mathrm{Sa}}\right) .
$$

This shows that the essential absence of $\Psi_{\mathrm{P}}^{\mathrm{Fs}}$ (obtained by measurement) requires $\Psi_{\Pi}^{\mathrm{Fs}}$ to be about equal to $\Psi_{\Pi}{ }^{\mathrm{Fa}}$
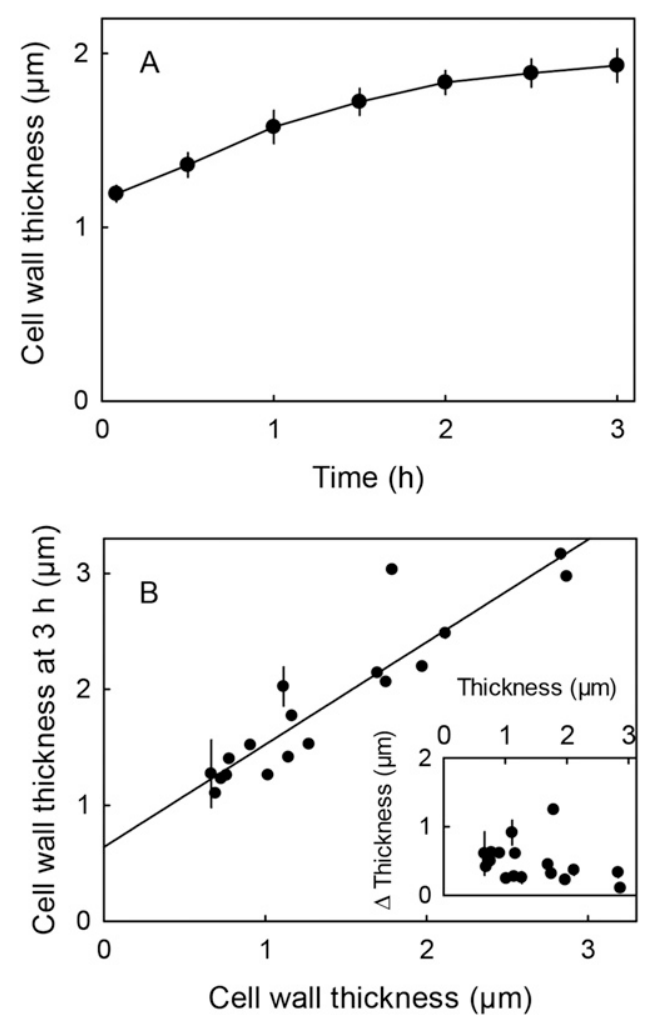

Fig. 5. Swelling of cell walls of epidermal cells of mature 'Sam' sweet cherry fruit. (A) Time course of cell wall swelling. (B) Relationship between thickness of cell walls after $3 \mathrm{~h}$ of swelling $\left(1^{3 \mathrm{~h}}\right)$ and the initial thickness before swelling $\left(1^{\text {oh }}\right)$. The regression equation describing this relationship was $1^{3 \mathrm{~h}}(\mu \mathrm{m})=0.88( \pm 0.09) 1^{0 \mathrm{~h}}(\mu \mathrm{m})+0.64( \pm 0.15), r^{2}=0.85, P<0.001$.

(Schumann et al., 2014). The value of $\Psi_{\Pi}{ }^{\text {Ss }}$ needs not be similar to $\Psi_{\Pi}^{\text {Sa }}$ or the epidermal cells would not be turgid.

Next, because $\Psi_{\Pi}{ }^{\text {Fs }}$ is much more negative than $\Psi_{\Pi}{ }^{\text {Ss }}$ (i.e., a major result presented in this study) $\Psi_{\Pi}^{\mathrm{Fa}}$ must be much more negative than $\Psi_{\Pi}{ }^{\text {Sa }}$. Such a difference in the osmotic concentrations of the two adjoining apoplasts (i.e., that of the flesh and that of the skin) requires postulation of a sharp gradient in osmolyte concentration along the planar interface between the apoplasts of the flesh and skin tissues. This gradient will likely generate a powerful concentrative driving force for the diffusion of osmolytes from flesh apoplast to skin apoplast. Similarly, it will generate a powerful water potential driving force for the diffusion of water in the reverse direction, from skin apoplast to flesh apoplast. Although plausible, or even inevitable, direct evidences for these counter-directional diffusions of osmolyte and water are lacking.

Table 3. Cell wall thickness between neighboring epidermal cells of mature 'Sweetheart' sweet cherry. Neighboring cells were either both living ("Living/living"), one living and one dead ("Living/ dead") or both dead ("Dead/dead") as indicated by the presence of a coagulated cytoplasm.

Status Cell wall thickness $(\mu \mathrm{m})$

Living/living $3.2 \pm 0.1 \mathrm{a}^{\mathrm{z}}$

Living/dead $3.4 \pm 0.1 \mathrm{a}$

Dead/dead $5.2 \pm 0.3 \mathrm{~b}$

${ }^{\mathrm{z}}$ Mean separation by Tukey's Studentized range test at $P=0.05$. 


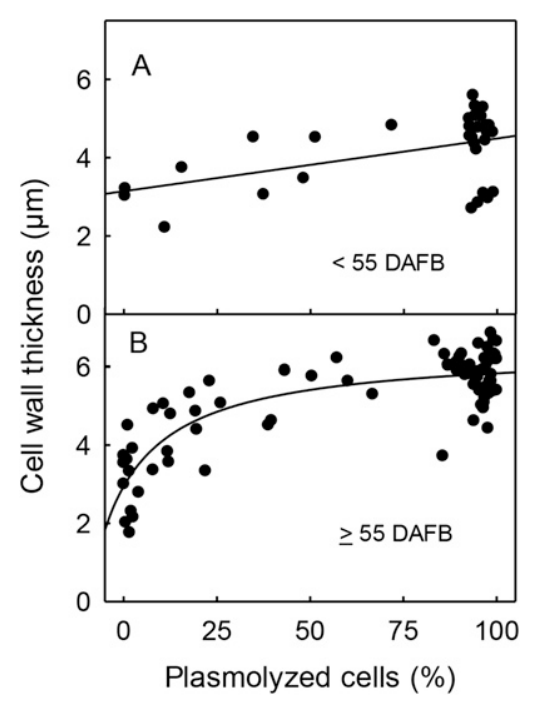

Fig. 6. Relationship between the thickness of epidermal cell walls and the percentage of plasmolyzed cells when incubating skin sections of sweet cherry fruit in sucrose solutions before (A) and after (B) $55 \mathrm{~d}$ after full bloom (DAFB).

If a large difference in osmolyte concentration is to be sustained between the apoplasts of the flesh and skin $\left(\Delta \Psi_{\Pi}\right)$, two possibilities remain. The first is that there is a diffusion barrier in the apoplast (equivalent to an endodermis) at the flesh-skin tissue interface that significantly impedes the counter-directional diffusions of osmolytes and water. The other possibility is that a standing difference $\left(\Psi^{\mathrm{F}}<\Psi^{\mathrm{S}}\right)$ is maintained actively by a continuous supply of carbohydrates to the flesh from the tree via the pedicel phloem, and/or on the other by a strong metabolic sink for carbohydrates in the skin. Although there does not seem to be a vascular system within the thin $(100 \mu \mathrm{m})$ skin layer, there is a prolific but fine network of ventral and dorsal vascular bundles in the outer flesh (mesocarp). The distribution of the vascular system is consistent with this hypothesis, but it would also require that the skin be very active metabolically so as to "use up" the major proportion of the centrifugally diffusing osmolytes (predominantly sugars).

Returning to the idea of an apoplastic barrier, the swollen cell walls of the skin could represent a significant diffusion resistance that slows progress toward osmotic and thus water potential equilibrium. Unlike the internal cuticle of tomato [Solanum lycopersicum L. (Matas et al., 2011)], there is no evidence for an internal transport barrier in sweet cherry fruit that could hydraulically "isolate" skin from flesh.

Based on the above arguments, the existence of a gradient in $\Psi$ between skin and flesh is a more likely explanation for the $\Delta \Psi_{\Pi}$, but definitive evidence is lacking. It is important to note that in both cases, the consequences would be similar, i. e., a driving force for diffusion of osmolytes from flesh to skin and for flow of water in the reverse direction from skin to flesh.

The broad range of osmotic potentials of bathing solutions (up to $1 \mathrm{MPa}$ and more) causing plasmolysis of fractions of epidermal cells of the very same fruit deserves some further comments (Fig. 2). Based on the arguments presented above, this range reflects the range of $\Psi_{\Pi}^{\mathrm{s}}$ of the epidermal cells indicating considerable heterogeneity within the population of cells in a given fruit. Assuming water potential equilibrium within the epidermis, we would expect a correspondingly broad range in their $\Psi_{\mathrm{P}}^{\mathrm{S}}$. Unfortunately, due to the small size of epidermal cells, direct evidence for this inference using pressure probe techniques is difficult to obtain.

Swelling of CELl WALls on Plasmolysis. Swelling of cell walls is commonly observed in ripening fruit that has a "soft and melting" texture, but not in fruit having a "crisp and fracturable" texture (Redgwell et al., 1997). Our observations in sweet cherry are consistent with this conclusion. According to Redgwell et al. (1997) swelling is thought to result from pectin solubilization and a subsequent increase in volume when water moves into voids of the cellulose-hemicellulose network formed on pectin solubilization and extraction. We observed increased swelling beyond 55 DAFB as compared with before 55 DAFB, which is in agreement with increased activity of pectinases during stage III of fruit development [Fig. 3 (Brummell, 2006; Kondo and Danjo, 2001)]. Unfortunately, little is known about the physical properties of swollen cell walls and we are not aware of published information quantifying the "osmotic" potentials and pressures exerted by the swelling and hydrating cell walls. Our data suggest 1) that the swelling pressure is probably low, whereas 2) the volume increase due to swelling is quite significant $[+0.64 \mu \mathrm{m}$ in width (Fig. 5A)]. First, cell wall swelling occurred only when living cells plasmolyzed and hence, turgor was absent. Second, cell wall swelling was greatest in cell walls separating two dead cells, intermediate for cell walls separating a dead from a living cell, and least when cell walls separated two living and turgescent cells. Apparently, in turgescent cells, the turgor balanced the swelling of cell walls. Because the turgor of cells of the outer mesocarp is lower than $0.1 \mathrm{MPa}$ at maturity (Knoche et al., 2014; Schumann et al., 2014), the pressure developed by swollen cell walls is expected to be of the same order of magnitude or slightly lower. This is of a similar magnitude to the swelling pressure reported for the starch biopolymer in potato [Solanum tuberosum L. (Jarvis et al., 1992)]. The volume increase of the apoplast due to cell wall swelling indicates significant water uptake, the forces driving this uptake are not yet known.

\section{Conclusion}

Our results provide direct and conclusive evidence for the existence of a marked difference $(1.1 \mathrm{MPa})$ in osmotic potential between the sweet cherry fruit skin and its flesh. The most likely explanation is a standing gradient in osmotic potentials where osmolytes accumulate in the flesh due to vascular import while the skin lags behind. From a practical point of view, the less negative osmotic potential of the skin has some interesting consequences: First, a less negative osmotic potential of the skin will prevent the development of significant turgor in the skin, where the bursting of epidermal cells would weaken the tissue as a load-bearing structure (Brüggenwirth et al., 2014). Second, a more negative osmotic potential in the flesh in the absence of significant turgor (Knoche et al., 2014; Schumann et al., 2014) would essentially "dehydrate" the skin thereby making the skin flaccid and hence more extensible as indexed by a decreased modulus of elasticity (Brüggenwirth, personal communication). Finally, as a further consequence, the skin may serve as a transient buffer that allows uptake into the cells and 
enhanced water transport into the flesh (driven by the skinflesh osmotic potential difference). All three effects would tend to render a fruit less susceptible to cracking.

\section{Literature Cited}

Beyer, M. and M. Knoche. 2002. Studies on water transport through the sweet cherry fruit surface: V. Conductance for water uptake. J. Amer. Soc. Hort. Sci. 127:325-332.

Brüggenwirth, M., H. Fricke, and M. Knoche. 2014. Biaxial tensile tests identify epidermis and hypodermis as the main structural elements of sweet cherry skin. Ann. Bot. Plants doi: 10.1093/ aobpla/plu019.

Brummell, D.A. 2006. Cell wall disassembly in ripening fruit. Funct. Plant Biol. 33:103-119.

Considine, J. and K. Brown. 1981. Physical aspects of fruit growththeoretical analysis of distribution of surface growth forces in fruit in relation to cracking and splitting. Plant Physiol. 68:371-376.

Considine, J.A. and P.E. Kriedemann. 1972. Fruit splitting in grapes. Determination of the critical turgor pressure. Austral. J. Agr. Res. 23:17-24.

Glenn, G.M. and B.W. Poovaiah. 1989. Cuticular properties and postharvest calcium applications influence cracking of sweet cherries. J. Amer. Soc. Hort. Sci. 114:781-788.

Grimm, E., S. Peschel, T. Becker, and M. Knoche. 2012. Stress and strain in the sweet cherry fruit skin. J. Amer. Soc. Hort. Sci. 137:383390.

Herrmann, K. 2001. Inhaltsstoffe von Obst und Gemüse. Ulmer, Stuttgart, Germany.

Jarvis, M.C., E. Mackenzie, and H.J. Duncan. 1992. The textural analysis of cooked potato. 2. Swelling pressure of starch during gelatinisation. Potato Res. 35:93-102.

Knoche, M., E. Grimm, and H. Schlegel. 2014. Mature sweet cherries have low turgor. J. Amer. Soc. Hort. Sci. 139:3-12.
Kondo, S. and C. Danjo. 2001. Cell wall polysaccharide metabolism during fruit development in sweet cherry 'Satohnishiki' as affected by gibberellic acid. J. Jpn. Soc. Hort. Sci. 70:178-184.

Matas, A.J., T.H. Yeats, G.J. Buda, Y. Zheng, S. Chatterjee, T. Tohge, L. Ponnala, A. Adato, A. Aharoni, R. Stark, A.R. Fernie, Z. Fei, J.J. Giovannoni, and J.K.C. Rose. 2011. Tissue- and cell-type specific transcriptome profiling of expanding tomato fruit provides insights into metabolic and regulatory specialization and cuticle formation. Plant Cell 23:3893-3910.

Measham, P.F., S.A. Bound, A.J. Gracie, and S.J. Wilson. 2009. Incidence and type of cracking in sweet cherry (Prunus avium L.) are affected by genotype and season. Crop Pasture Sci. 60:1002-1008.

Moing, A., C. Renaud, H. Christmann, L. Fouilhaux, Y. Tauzin, and A. Zanetto. 2004. Is there a relation between changes in osmolarity of cherry fruit flesh or skin and fruit cracking susceptibility? J. Amer. Soc. Hort. Sci. 129:635-641.

Redgwell, R.J., E. MaxRae, I. Hallett, M. Fischer, J. Perry, and R. Harker. 1997. In vivo and in vitro swelling of cell walls during fruit ripening. Planta 203:162-173.

Schumann, C., H.J. Schlegel, E. Grimm, M. Knoche, and A. Lang. 2014. Water potential and its components in developing sweet cherry. J. Amer. Soc. Hort. Sci. 139:349-355.

Steudle, E. 1993. Pressure probe techniques: Basic principles and application to studies of water and solute relations at the cell, tissue and organ level, p. 5-36. In: J.A.C. Smith and H. Griffiths (eds.). Water deficits: Plant responses from cell to community. Bios Scientific Publishers, Oxford, UK.

Wada, H., K.A. Shackel, and M.A. Matthews. 2008. Fruit ripening in Vitis vinifera: Apoplastic solute accumulation accounts for preveraison turgor loss in berries. Planta 227:1351-1361.

Wada, H., M.A. Matthews, and K.A. Shackel. 2009. Seasonal pattern of apoplastic solute accumulation and loss of cell turgor during ripening of Vitis vinifera fruit under field conditions. J. Expt. Bot. 60:1773-1781. 